\title{
GOT HEALTH? ADVERTISING, MEDICAID AND CHILD HEALTH
}

\author{
Anna Aizer* \\ Brown University
}

October 1,2003

Of the ten million uninsured children in 1996, nearly half were eligible for Medicaid, the public health insurance program for poor families, but not enrolled. In response, policy efforts to improve coverage have shifted to increasing Medicaid take-up among those already eligible rather than expanding eligibility. However, little is known about the reasons poor families fail to use public programs or the consequences of failing to enroll. The latter is of particular relevance to Medicaid given that children are typically enrolled when they become sufficiently sick as to require hospitalization. Using detailed information on Medicaid outreach, enrollment and hospitalization rates in California, I find that 1) information and administrative costs are important barriers to program enrollment, and 2) enrolling children in Medicaid before they require hospitalization leads to a more efficient allocation of health care resources and better health by promoting preventative ambulatory care over more expensive hospital based care.

aizer@brown.edu. I am extremely grateful for the advice and support of Janet Currie. I also thank Pedro Dal Bó, Jeff Grogger, Joe Hotz and Guido Imbens as well as seminar participants at UCLA, Princeton and Brown Universities and the NBER Children's meeting. Jim Klein and Kennalee Gable of the California Department of Health Services generously provided the data. Financial support from the Social Science Research Council, Program in Applied Economics and the California Program on Access to Care is gratefully acknowledged. 
In 1996, ten million US children were without health insurance and nearly half a million children were hospitalized unnecessarily [Fronstin, 1998; Graves, 1998]. Despite the lack of empirical evidence linking insurance coverage and unnecessary or avoidable hospitalizations, policymakers have often argued that increasing coverage would lead to a decline in unnecessary hospitalizations in support of efforts to increase eligibility for public health insurance. However, nearly half of the ten million children without insurance were already eligible for Medicaid, the public health insurance program for poor families, but not enrolled [Selden, Banthin, and Cohen, 1998]. As a result, recent debate over improving health insurance coverage has shifted away from eligibility expansions to increasing enrollment or take-up among those already eligible but not enrolled.

However, because eligible children are often enrolled in Medicaid when care is needed, it is likely that those who choose not to enroll are relatively healthy and as such perceive little benefit to obtaining health insurance given the costs of applying. A policy promoting enrollment among this group presumes that they would benefit from health insurance coverage and would choose to enroll if the costs were sufficiently lowered - a presumption with little empirical basis. Thus, the two key questions for this debate are 1) what are the costs to poor families of enrolling in public programs, such as Medicaid, and can they be sufficiently lowered so as to encourage enrollment, and 2) whether enrollment of relatively healthy children in public health insurance programs before medical attention is needed has any positive impact on either the efficiency or effectiveness of the program in improving their health. In other words, is there any benefit to enrolling children in a public health insurance program before medical care is needed?

With respect to the first question of low take-up, little is known about the reasons one third to one half of poor families fail to use public programs that involve no out-of-pocket costs but likely involve other costs such as information costs associated with learning about the program and process or administrative costs associated with applying for benefits. Though much 
has been written about the potential costs of enrolling in public programs, empirical evidence is lacking. The inherent difficult in estimating the costs associated with program enrollment lies in the fact that factors affecting both the costs and benefits of enrollment likely vary among eligible individuals in ways unobservable to the researcher. In a review of the existing literature on program take-up, Remler, Rachlin and Glied [2001] conclude that of the factors determining program (including Medicaid) participation "what little evidence about their effects exists is primarily qualitative and self-reported, based on focus groups and reports of officials. Their quantitative magnitude is entirely unknown.”

Nor is there much evidence with respect to the second question - whether early enrollment in Medicaid leads to gains in efficiency or health. Unlike the food stamp or cash welfare programs for which lack of program participation results in lack of any benefit, poor children who are eligible for Medicaid but who fail to enroll will be cared for (by law) should they become ill and require hospitalization. Not only will they be cared for, but their care will be covered by Medicaid since eligible uninsured children are nearly always enrolled in Medicaid when they present at the hospital. The potential benefit of enrolling more children in Medicaid prior to their requiring hospitalization lies in its promotion of the efficient use of health care resources by increasing financial access to ambulatory preventative care prior to hospitalization, resulting in fewer hospitalizations, lower costs and better health. Again, however, estimation of the impact of enrollment in Medicaid on health care utilization and child health is hindered by the endogeneity of the enrollment decision (children who are less healthy and thus in greater need of medical care are more likely to enroll). As such, OLS estimates of the impact of Medicaid enrollment on hospitalization rates are likely to be downward biased. Meaningful estimates of the impact of early enrollment in Medicaid requires an identification strategy that overcomes this endogeneity. 
Thus the purpose of this research is two-fold: 1) to better understand the causes of low take-up in public programs, and 2) to estimate the benefit of early enrollment in terms of efficiency and improved health brought about by the prevention of unnecessary hospitalizations, accounting for the endogeneity of Medicaid enrollment. To answer these questions I use a unique dataset that combines information on the timing and placement of Medicaid outreach efforts in California with administrative data on both Medicaid enrollment and hospitalization for the period 1996-2000 at a very fine level of detail (the zipcode and month). Identification follows from the exogenous variation in outreach efforts brought about by California's outreach campaign launched in mid 1998 which consists of a media campaign and the recruitment of community based organizations (CBOs) often with bilingual staff to serve as application assistants.

I find the most profound effects of outreach on those with the highest costs of enrolling: Hispanic and Asian children who have greater language and immigration concerns than other families. Proximity to an additional bilingual application assistant increases new monthly Medicaid enrollment among Hispanics by 16 to 46 percent and among Asian children by 26 to 45 percent. An additional week of English language advertising appears to have no effect on new enrollment. However, a week of Spanish language advertisements increases new enrollment among Hispanic children by nearly nine percent. These results have important implications not only for improving Medicaid coverage among poor children, but also for increasing take-up in other programs such as food stamps and the EITC.

To estimate the benefit of early program take-up, I examine the effect of Medicaid enrollment (as a function of state outreach efforts) on avoidable, ambulatory care sensitive (ACS) hospitalizations in California in a two stage estimation process in which outreach efforts serve as instruments in the first stage. ACS conditions are defined as those "diagnoses for which timely and effective ambulatory care can help to reduce the risks of hospitalization by either preventing 
the onset of an illness or condition, controlling an acute episodic disease or condition."1 If greater numbers of children are responding to local outreach efforts and enrolling in Medicaid prior to hospitalization, then we expect access to regular ambulatory care to improve and the rates of avoidable ACS hospitalizations to decline.

I find that increased take-up does lead to lower hospitalization rates for those conditions that are avoidable if timely and effective ambulatory care is received. Using instrumental variables, I find that increasing the number of children with Medicaid by 25 percent (prior to requiring hospitalization) results in a decline in avoidable Medicaid hospitalizations by 3.4 percent. These findings suggest that local efforts to increase take-up of Medicaid result in more efficient use of health care resources, fewer avoidable hospitalizations, and better health.

The rest of the paper is laid out as follows: section I surveys the existing literature on outreach and Medicaid take-up, access to primary care and factors affecting avoidable hospitalizations, section II provides background on California's outreach program, section III presents implications of a model of Medicaid enrollment in the face of fixed enrollment costs, section IV presents the empirical strategy and results of the analysis of the effect of outreach on enrollment, section $\mathrm{V}$ the results of the analysis of the impact of increases in enrollment on hospitalizations, and section VI concludes.

\section{Existing Literature}

\section{A. Medicaid Take-Up}

Though Medicaid has no out of pocket costs and lowers the cost of medical care faced by low-income families, many still fail to enroll: nearly half of all uninsured children in California are eligible for Medicaid but not enrolled. The three main reasons for low take-up, as hypothesized in the literature, are 1) lack of information (information costs), 2) administrative

\footnotetext{
${ }^{1}$ Billings, John and Nina Teichholz [1990]. "Uninsured Patients in District of Columbia Hospitals,"
} 
hassle associated with an application that requires considerable paper-work, verification of income and visits with caseworkers (process costs), and 3) and stigma associated with public programs (outcome costs). In addition, these costs vary by certain family characteristics: those with language barriers or immigration concerns likely face higher information and process costs and new families (those with infants) whose potential exposure to the Medicaid program may be shorter, may face higher information costs.

What empirical work on Medicaid take-up exists consists largely of focus groups and case-studies, the results of which may not be generalizeable to the population of uninsured children. Three qualitative evaluations of Medicaid take-up in California suggest that process and information costs are the main concerns for this population. A series of focus groups on Medicaid enrollment in California revealed that confusion over eligibility, language barriers, fears about immigration and an onerous enrollment process were considered important barriers by eligibles [Perry, Stark and Valdez 1998; Perry 2001]. ${ }^{2}$ Findings from market research based on a sample of families eligible but not enrolled conclude that concerns over the enrollment process (long applications and waiting periods) are far more significant barriers to enrollment than concerns related to eligibility, coverage, benefits, costs, physician availability and documentation requirements [Medi-Cal Policy Institute, 2000].

Two conclusions can be drawn from this literature. First, information costs include a lack of knowledge of the current enrollment process, not simply awareness of the program. And second, process costs associated with enrollment in Medicaid are perceived to be high by California Medicaid eligibles, especially those with language barriers and/or immigration concerns - primarily the Asian and Hispanic populations in California.

\footnotetext{
Health Affairs, 9, 158-165.

${ }^{2}$ Immigration concerns consist of fears of deportation among those in the US without proper documentation and for those with documentation, fears of being considered a "public charge" which could lead to deportation.
} 


\section{B. Avoidable Child Hospitalizations}

Children accounted for roughly nine percent of all acute care hospitalizations (excluding births) in California and a slightly larger percentage of total acute care hospital expenditures in 1999. Many of those hospitalizations were likely avoidable. Previous estimates suggest that eighteen to 28 percent of all child hospitalizations are avoidable or ambulatory care sensitive (ACS) compared with seven to twelve percent of adult, non-elderly hospitalizations [McConnochie et al, 1997]. There is strong evidence that high ACS hospitalization rates do reflect inadequate ambulatory care. Parchman and Culler [1994] analyze hospital discharge data in Pennsylvania and find that areas with more general practice physicians have lower rates of ACS hospitalizations, controlling for other environmental characteristics that might affect hospitalization rates. Research by Shi et al [1999] based on hospital discharges in South Carolina finds that those children without a primary care provider were nearly ten times more likely to be hospitalized for an ACS condition than those with a primary care provider. Gadmoski et al [1998] evaluated a Medicaid managed care program in Maryland that emphasized improved access to primary care and found a decline in child hospitalization rates, particularly for ACS conditions. $^{3}$

Though the link between ACS hospitalizations and access to primary care is wellestablished, the link between ACS hospitalizations and insurance is more tenuous because of the presence of unobserved characteristics correlated with both the insurance decision and utilization that are more difficult to control for than are factors affecting access to primary care. If underlying factors, such as initial health status, care-seeking behavior, or poverty, are associated with Medicaid enrollment and with rates of ACS hospitalizations, then Medicaid enrollment is endogenous, complicating estimation of its impact on ACS hospitalizations. Work by Kaestner,

\footnotetext{
${ }^{3}$ Other studies include Gill and Mainous [1998] who find that provider continuity is associated with fewer hospitalizations for chronic ACS conditions, but not acute ACS conditions among children in Delaware. Finally, Epstein [2001] finds that the availability of ambulatory clinics is associated with better access to primary care and a decline in ACS hospitalizations among low-income elderly populations in Virginia.
} 
Joyce and Racine [1999] and Dafny and Gruber [2000] represent efforts to control for these factors in estimates of the impact of Medicaid eligibility expansions on child hospitalization. The authors identify the effect of making more children eligible for Medicaid coverage using variation across states over time (as the Medicaid expansions were implemented at different times and different states. $)^{4}$ While Kaestner, Joyce and Racine [1999] find mixed evidence regarding the impact of Medicaid expansions on ACS hospitalizations, Dafny and Gruber [2000] find stronger evidence that expanding Medicaid eligibility to include previously ineligible children decreases the number of ACS hospitalizations though it increases the total number of hospitalizations.

The question raised and answered in this paper, however, differs in important ways from that of Kaestner, Joyce and Racine [1999] and Dafny and Gruber [2000]. In this paper I estimate the impact not of expanding eligibility to additional children, but of program take-up among children already eligible. I also use considerably more detailed data (zipcode level versus state level), enabling me to control for many factors, observed and unobserved, that vary at a local level and may affect both Medicaid enrollment and child health, as well as a novel identification strategy.

\section{Background on Medicaid and Outreach in California}

\section{A. Medicaid Eligibility}

Children in California qualify for Medicaid through multiple channels. The most common channel (67 percent of all Medicaid covered children in 1996) is through the cash welfare program - AFDC/TANF. All children on welfare are automatically eligible for Medicaid and thus face zero costs of enrollment in Medicaid. The next most common means of Medicaid enrollment among children are through the Medicaid poverty expansion and medically needy

\footnotetext{
${ }^{4}$ Their method relies on the inclusion of state and time fixed effects to control for unobservables correlated with Medicaid coverage and hospitalization rates. They also exploit some within state variation as the Medicaid expansions included children of some ages, and not others.
} 
programs, and, more recently, the federal section 1931(b) program. The outreach programs developed by the state target families eligible through these mechanisms. ${ }^{5}$

\section{B. Trends in Child Medicaid Enrollment}

Child Medicaid enrollment in California peaked in 1995 and then began to decline (Figure I). The driving force behind the decline in Medicaid enrollment has been drastically falling welfare rolls in California that have been partially offset by a rise in children enrolled through other non welfare-related channels that began in mid 1998. For Hispanic children, increased enrollment though other channels offsets the declines in welfare-related Medicaid enrollment to a greater extent than for the population as a whole, resulting in a net increase in total Hispanic Medicaid enrollment between 1998 and 2000 (Figure II).

As Figuress I and II illustrate, the decline in Medicaid enrollment through the welfare program precedes the increase in enrollment through other programs. Medicaid coverage through the welfare program begins to decline in 1995-1996, while the increased enrollment in non welfare-related programs does not begin until 1998, coincident with the implementation of the state's outreach program in June of that year. This suggests that the rise in non welfare-related Medicaid enrollment does not simply reflect a transfer of enrollment from welfare-related enrollment as AFDC/TANF caseloads decline.

\section{California's Uninsured and the Medicaid Outreach Campaign}

A 1999 study of the uninsured in California estimated that of the 1.8 million uninsured children in the state, nearly 800,000 were eligible for Medicaid and among those eligible, 60

\footnotetext{
${ }^{5}$ In California, the poverty expansions extend Medicaid eligibility to infants up to $200 \%$ of the federal poverty level (FPL), children under 6 up to $133 \%$, children 6-15 up to $100 \%$ and children ages 15 and older up to $82 \%$ of the FPL. California's medically needy program is a relatively generous program, providing coverage to families with income roughly one third higher than current AFDC/TANF levels. The 1931(b) program (implemented in January 1998) stipulates that all families with income below 100 percent FPL are eligible for Medicaid.
} 
percent were Hispanic. ${ }^{6}$ Such low rates of take-up among the Hispanic population are consistent with their facing greater costs of enrolling due to language barriers and/or immigration concerns.

California's outreach campaign was launched in June, 1998 coincident with the launching of the state's SCHIP program, entitled Healthy Families, which expanded coverage to children in families with income above Medicaid eligibility thresholds but below 250 percent of the federal poverty level through a separate, non-Medicaid program. The outreach campaign targets both the 800,000 uninsured children eligible for Medicaid but not enrolled and an additional 325,000 newly eligible for Healthy Families. The outreach campaign is comprised of two main components: community-based application assistants to reduce the process and outcome costs of enrolling, and a multi-million dollar media campaign to increase awareness of the program and reduce the information costs of enrolling, with roughly seven million dollars devoted to each component in the first year. ${ }^{7}$ In addition, the state made great efforts to simplify the enrollment process by developing a mail-in application that was considerably shorter in length than the previous application (reduced from 20 pages in June, 1998 to four by April,1999). The two main components are discussed in turn below.

\section{Community Based Application Assistants (CBOs)}

Community based application assistants (CBOs) are non-profit community organizations that are trained by the state in the completion of Medicaid applications. This component of the outreach campaign is designed to lower the process or application costs of enrollment. CBOs do not represent new organizations placed in the community for the purpose of conducting outreach and enrollment, but are pre-existing organizations. For all applications received and approved by the state, a $\$ 50$ fee is granted to the application assistant. Nearly half of the $1,100 \mathrm{CBOs}$

\footnotetext{
${ }^{6}$ This study was conducted by the UCLA Center for Health Policy and based on the 1998 March CPS.

${ }^{7} \mathrm{~A}$ third component, the granting of funds to community based organizations to conduct outreach, was initially small but has recently increased in size. In the first year of the campaign, roughly $\$ 7$ million was
} 
providing assistance in the first year of the program were health care providers and clinics

(hospitals are not eligible), 20 percent were community service organizations and 9 percent were schools. ${ }^{8}$ Half of the CBOs have bilingual staff.

Over time, access to CBOs has increased. In 1998, 28 percent of all zipcodes had a CBO, increasing to 39 percent in 1999 and 46 percent by 2000. By March of 1999, ten months after the campaign was launched, half of all Medicaid applications received by the state were completed with the assistance of a community based organization and over \$1 million in application assistance fees had been paid to CBOs.

Figure III presents trends in non welfare-related Medicaid enrollment among Hispanics that gain access to one, two to four, and five or more CBOs over this period. While differences in initial levels between these groups exist, they are relatively small. However, beginning in June 1998, the differences in non welfare-related Medicaid enrollment among these groups increased proportionately with the number of $\mathrm{CBOs}$ located in those areas. Hispanics living in areas that gain access to greater numbers of CBOs exhibited a greater increase in enrollment relative to Hispanics that gained access to fewer numbers of CBOs. ${ }^{9}$ The non random placement of CBOs suggests possible selection on location which I address in Section IV.

\section{The State Advertising Campaign}

The state advertising campaign consists primarily of television, and to a lesser extent radio and print advertisements that run in 48 of the state's 58 counties. The advertisements were developed in both English and Spanish languages and were designed to lower the information

allocated to advertising. For the community-based application assistants, $\$ 2.1$ million was allocated for the payment of a \$50 fee for each completed application, \$1.9 million for training and \$2.7 million for support. ${ }^{8}$ The remainder include insurance agents (5\%), faith based organizations (3\%), hospitals (3\%) and taxpreparers $(1 \%)$.

${ }^{9}$ To determine whether CBOs are located in areas with greater declines in welfare-related Medicaid coverage that may affect the underlying demand for non welfare-related Medicaid coverage and thus bias the results, I examine trends in welfare-related Medicaid enrollment for the same groups. Bilingual CBOs are placed in poor areas that are characterized by higher initial levels of welfare use (among all groups, not 
costs of enrollment. The advertising campaign was launched in June, 1998 and in the first 30 months of the program, television advertisements were aired in at least one county in all but seven months, with advertisements running from one to four weeks per month. All campaign materials consistently promote a toll-free number and in 1999, the state added banner copy to Spanish language ads that read "Call Now."10

The state largely considers the state-wide media campaign a success, based on the fact that calls to the toll-free hotline double in the weeks during which commercials have aired (from roughly 800 calls/day to 1900 calls/day), and that 30 percent of callers identified advertising as their primary source of information about Medicaid. However, the state does not know what proportion of calls result in application and enrollment.

\section{Medicaid Enrollment and Selection}

There are two main implications of a simple economic model of enrollment in Medicaid (which lowers the cost of purchasing medical care but includes fixed costs of participation). First, if the fixed costs of participation decrease (through, for example, an outreach campaign), families will be more likely to participate. Those for whom the cost decrease is greater as a result of outreach (Hispanic and Asian families with language barriers and new families with the least exposure to Medicaid), the probability of enrollment will likewise be greater. Second, given the likelihood of negative correlation between underlying (and unobserved) health and the enrollment decision, as the costs of enrollment decrease, the average health of those enrolling will increase.

The possibility of selection effects with respect to health insurance coverage in the presence of fixed enrollment costs has important implications for the results of the analysis of the impact of a decrease in the costs of health insurance on hospitalization. OLS regression of

\footnotetext{
just Hispanics), but the rates of decline appear similar for all groups.

${ }^{10}$ The toll-free line is staffed Monday - Friday $8 \mathrm{am}$ to $8 \mathrm{pm}$ by a team of operators proficient in ten languages who respond to requests for applications, assist with questions about the application, and provide referrals to $\mathrm{CBOs}$.
} 
hospitalization on Medicaid coverage will result in upward biased estimates of the impact of Medicaid coverage on hospitalization - as the number of sick children increases, so will Medicaid enrollment and hospitalization rates. My estimation strategy which involves instrumenting for Medicaid coverage using outreach as instruments is designed to eliminate this selection bias, allowing identification of the impact of early Medicaid enrollment on preventative ambulatory care and avoidable hospitalizations.

\section{The Effect of Outreach on Medicaid Enrollment}

\section{A. $\underline{\mathrm{CBOs}}$}

\section{Data and Empirical Strategy}

To assess the impact of lowering process costs on new Medicaid enrollment, I link data on CBO placement with monthly data on new Medicaid enrollment by zipcode, race, and month for February 1996 to December 2000. ${ }^{11}$ CBO availability or access is defined as the number of CBOs in one's zipcode as of the first month of enrollment. Because Medicaid coverage begins on the date of application, this is equivalent to access to CBOs as of the date of application. It is important to note that the analysis is limited to identifying the impact of outreach on Medicaid enrollment only, excluding enrollment through the new SCHIP program, Healthy Families, in an attempt to isolate the effect of outreach on take-up among those already eligible but not enrolled and not on those made newly eligible for public health insurance. This is an important distinction between this work and previous work which examines the impact of expanding eligibility for health insurance coverage on health outcomes, not of increasing take-up among those already eligible. $^{12}$

\footnotetext{
${ }^{11}$ Children enrolled in Medicaid through SSI or fostercare are excluded.

${ }^{12}$ During this period, the launching of the 1931(b) program expanded eligibility to all persons below $100 \%$ of the FPL. Though all children below the FPL in California were already eligible through the poverty expansions (except those over 14 who were eligible up to $82 \%$ of the FPL), it is possible that this increase in eligibility may have independently increased the number of children applying for Medicaid. However,
} 
To identify the impact of CBOs on Medicaid enrollment, I employ multiple strategies to account for possible selection in their placement or timing that may be based on demand for these services. First, zipcode and month fixed effects are included to control for the fact that areas with more intense outreach efforts may have higher numbers of low-income children, and general trends in enrollment over this time period, respectively. Also included are other covariates that control for changes in the business cycle and in the underlying demographic composition of the state that may affect the demand for health insurance: the annual county employment to population ratio from BEA employer surveys (EMP/POP) and the number of births to women without a college degree by race, zipcode and year from California birth certificate records (BIRTHS).

This basic equation has the following form:

$$
\begin{aligned}
\mathrm{M}_{\mathrm{rzt}}=\beta_{0} & +\beta_{1} \mathrm{ENGCBO}_{\mathrm{zt}}+\beta_{2} \mathrm{SPCBO}_{\mathrm{zt}}+\beta_{3} \mathrm{ASNCBO}_{\mathrm{zt}}+\beta_{4} \mathrm{HISP}^{*} \text { SPCBO }_{\mathrm{rzt}} \\
& +\beta_{5} \text { ASIAN }^{*} \text { ASNCBO }_{\mathrm{rzt}}+\beta_{6} \text { RACE }_{\mathrm{r}}+\beta_{8} \text { BIRTHS }_{\mathrm{rzt}} \\
& +\beta_{9}{\mathrm{EMP} / \mathrm{POP}_{\mathrm{ct}}}+\beta_{10} \mathrm{MONTH}_{\mathrm{t}}+\beta_{11} \text { ZIPCODE }_{\mathrm{z}}+\mathrm{v}_{\mathrm{rzt}}
\end{aligned}
$$

$\mathrm{M}_{\mathrm{rzt}}$ is the $\log$ of new Medicaid enrollment for race $\mathrm{r}$ at time $\mathrm{t}$ in zipcode $\mathrm{z}$. New enrollment is defined as not having any Medicaid coverage in the month before. This controls for any changes in type of enrollment that would not reflect new enrollment (ie, children losing cash welfare benefits but remaining enrolled in Medicaid through other channels - either transitional Medicaid or $1931 \mathrm{~b}) . \mathrm{ENGCBO}_{\mathrm{zt}}$ is the number of community based application assistants without bilingual staff in the zipcode in the month of enrollment, $\mathrm{SPCBO}_{\mathrm{zt}}$ is the number of CBOs with Spanishspeaking staff. Spanish-speaking CBOs are interacted with a dummy for Hispanic (HISP*SPCBO ${ }_{\mathrm{zt}}$ in the above equation), while Asian speaking $\mathrm{CBOs}\left(\mathrm{ASNCBO}_{\mathrm{zt}}\right)$ are interacted with a dummy for Asian, (ASIAN*ASNCBO ${ }_{\text {zt }}$ ). In addition I include race (white, black, Hispanic 
and Asian) indicators. All analyses are weighted by the size (population) of the cell. ${ }^{13}$

In additional specifications, I include further controls for the possibility of selective timing and placement of CBOs that may bias the results. First, I include zipcode*year fixed effects. This limits the identifying variation to changes in access to CBOs that occur within a relatively short period, thereby minimizing potential unobserved underlying differences between those areas that quickly gained access to a $\mathrm{CBO}$ and those with delayed access. To control for the possibility that Hispanic and Asian families residing in areas that gain access to bilingual CBOs may differ from those who do not, I interact Hispanic and Asian children with an indicator for whether they ever gained access to a CBO: Hisp*EverSPCBO and Asian*EverASNCBO. Finally, I include zipcode*year*month fixed effects to control for zipcode-specific changes over time in enrollment patterns.

\section{Results: The Impact of CBOs on New Medicaid Enrollment}

The first column of Table I contains estimates of the impact of CBOs on the log of total new enrollment with zipcode and month fixed effects for the period February 1996-December 2000 (equation 1a). As is evident from the table, the greatest effects are those found for bilingual CBOs on Hispanic and Asian enrollment (Spanish language CBO*Hispanic and Asian language $\mathrm{CBO}^{*}$ Asian). The estimates suggest that an additional Spanish language CBO increases total new monthly Medicaid enrollment for Hispanic children by 16 percent, while an additional Asian language $\mathrm{CBO}$ increases enrollment by 25 percent among Asian children. Interestingly, the main effects of bilingual CBOs are negative and significant for Hispanic and English only CBOs (0.035 and -0.069 ). This suggests the possibility of selection effects in the timing and/or location of outreach efforts.

To account for this possibility, columns two through four of Table 1 present estimates

\footnotetext{
${ }^{13}$ The population of the cell is defined as all families of a given race below $200 \%$ of the FPL residing in
} 
from regressions that include increasingly restrictive controls. Column two includes zipcode*year and month fixed effects and column three includes the additional variables mentioned previously (Ever gain access to a Spanish CBO*Hispanic and ever gain access to an Asian CBO*Asian) which control for the possibility that Hispanics and Asians in zipcodes that gain access to a CBO differ significantly from those who do not. When these additional controls are included, the main effect Spanish CBOs on enrollment disappears and the impact of English CBOs becomes positive and significant while the main effect of Asian language CBOs becomes negative. In addition, the coefficients on the interaction terms increase in magnitude to 0.228 and 0.350 , respectively, for Hispanics and Asians.

Finally, column four of Table 1 includes zipcode*year*month fixed effects, controlling for the possibility that zipcodes may exhibit different trends in enrollment over this period and that the positive effect of CBOs on enrollment may in fact reflect such differences. Once this more restrictive control is included, the impact of bilingual CBOs on total new Hispanic and Asian enrollment (column 4) increases considerably, roughly doubling in size from the estimates with the least restrictive controls presented in column 1 . These results suggest that potential selection in the placement of CBOs may, if anything, underestimate the true effects of bilingual outreach on Medicaid take-up.

In Table 2, I present estimates similar to those presented in column 4 of Table 1, except the outcome is not the log of new monthly enrollment but new enrollment. In addition, I break out enrollment by source - welfare related or non welfare related. Column 1 presents estimates for total new monthly Medicaid enrollment, column 2 for new non-welfare related enrollment and column 3 for new welfare-related enrollment. As discussed previously, we expect outreach to have a greater impact on non welfare related enrollment relative to welfare related enrollment and in fact, the estimates suggest this to be the case. Bilingual outreach appears to have a much

the zipcode as determined by the 2000 decennial census. 
greater impact on non-welfare related enrollment among both Hispanics and Asians with each additional bilingual CBO increasing total new monthly Medicaid enrollment by 26 and 6 new children per month, respectively, of which 23 and 4 children are enrolled outside the cash welfare system.

Finally, in order to explore the possibility that the effect of CBOs is non- linear in nature and whether there may be diminishing returns, I present estimates of the impact of the first CBO, second $\mathrm{CBO}$, etc. on the log of total new enrollment in Table 3. As is evident from the table, it appears that for the first $2 \mathrm{CBOs}$, the relationship is linear with two CBOs resulting in roughly double the percent increase enrollment as one CBO. However, the impact appears to plateau once two-four CBOs are available, increasing slightly with five or more CBOs. There is not any marginal increase associated with CBOs in excess of five.

\section{B. ADVERTISEMENTS}

\section{Data and Empirical Strategy}

To assess the influence of advertisements on new Medicaid enrollment, data on the timing of advertisements was linked to monthly Medicaid enrollment at the designated market area (DMA), of which there are 12 in California. ${ }^{14}$ The following equation was estimated:

$$
\begin{gathered}
\mathrm{M}_{\mathrm{rdt}}=\beta_{0}+\beta_{1} \text { ENGADVT }_{\mathrm{dt}}+\beta_{2} \text { SPADVT }_{\mathrm{dt}}+\beta_{3} \text { HISP }^{*} \text { SPADVT }_{\mathrm{rdt}}+ \\
\beta_{4} \text { RACE }_{\mathrm{r}}+\beta_{5} \text { MONTH }_{\mathrm{t}}+\beta_{6} \text { YEAR }^{*} \text { DMA }_{\mathrm{d}}+\varepsilon_{\mathrm{rdt}}
\end{gathered}
$$

$\mathrm{M}_{\mathrm{rdt}}$ is the $\log$ of new Medicaid enrollees in the DMA. ENGADVT ${ }_{\mathrm{dt}}$ is a variable equal to the number of weeks of television advertising in the month of enrollment, SPADVT ${ }_{\mathrm{dt}}$ is a measure of the number of weeks of bilingual (English and Spanish language) television advertising in the month of enrollment. The analysis sample excludes the ten counties in which advertisements

\footnotetext{
${ }^{14}$ A DMA is a media market, of which there are 12 in California: Bakersfield, Chico, El Centro, Eureka, Fresno, Los Angeles, Monterey, Palm Springs, Sacramento, San Francisco, Santa Barbara and San Diego.
} 
were never aired as they are substantially different (mostly rural) counties. Identification of the impact of advertisements is more straight-forward than the impact of CBOs because selection is less of an issue once we eliminate those counties that do not ever air an advertisement: monthly differences in the number of weeks of advertisements are determined by an advertisement schedule set at the beginning of the year and changes little from year to year.

\section{Results: the Impact of Advertising on New Medicaid Enrollment}

The results presented in Table 4 suggest that general English-language advertisements have no effect on the log of new enrollment, while targeted Spanish language advertisements increase enrollment among Hispanic children. Column (1) presents results based on equation $1 \mathrm{~b}$. English-language advertisments appear to have no effect on enrollment, Spanish-language advertisements appear to have a negative and significant effect on enrollment (-0.126), while Spanish-language advertisements interacted with Hispanic has a large and positive impact on new enrollment (0.218) for an overall increase in enrollment of 8.9 percent for Hispanic children.

In column (2) of Table 4, I include advertisements in the month AFTER enrollment, as a falsification check. As is evident from the table, advertisements in the month after have a very small and insignificant effect on enrollment and their inclusion has no impact on the estimates of advertisements in the month of enrollment on new enrollment. Finally, in column (3) I present results with DMA*YEAR*MONTH fixed effects to control for any DMA-specific time trends that may be driving the results. The estimate of the impact of Spanish advertisements on new enrollment among Hispanic children remains unchanged and the estimated impact of Spanish advertisements in the month after enrollment is close to zero and imprecisely estimated.

It is interesting to note that additional regressions, not presented here, in which the impact of advertisements in previous month on enrollment were estimated yielded a considerably smaller estimated impact of advertisements on enrollment, suggesting that the impact of advertising on 
enrollment is immediate, with less evidence of cumulative or lagged effects. This is consistent with a model in which advertisements serve to remind families to apply for Medicaid, rather than serving to inform or persuade them.

\section{The effect of Outreach and Enrollment on Avoidable Hospitalizations}

\section{A. Data and Empirical Strategy}

To estimate the impact of increased enrollment in Medicaid through outreach on access to primary, preventative care, I estimate the impact of outreach on child hospitalizations using instrumental variable methods. For this analysis, data on Medicaid enrollment in January, April, July, and October of each year (1996-2000) were matched to all Medicaid hospital admissions occurring in the following quarter by zipcode and race. ${ }^{15}$ Medicaid admissions was chosen as the outcome variable instead of all child admissions for the following reason: because poor uninsured children who present at the hospital are automatically enrolled in Medicaid by hospital staff at the time of admission, very few children are listed as uninsured in the hospital discharge data and thus, defining the outcome variable as all Medicaid hospitalizations is equivalent to all hospitalizations for Medicaid-eligible children (both those enrolled before hospitalization and those unenrolled). Hospital admissions are classified as either ambulatory care sensitive (ACS), defined as those "diagnoses for which timely and effective ambulatory care can help to reduce the risks of hospitalization by either preventing the onset of an illness or condition, controlling an acute episodic disease or conditions" [Billings, 1993], or as marker conditions which include acute appendicitis, congenital heart disease, and certain forms of cancer which should not be affected by access to primary care. ${ }^{16}$

${ }^{15}$ Data on all hospital admissions for California came from the hospital discharge database maintained by OSHPD which includes the diagnoses, payment source, age and race of the patient, and zipcode of residence.

${ }^{16}$ ACS conditions include asthma, bronchitis, bacterial pneumonia, dehydration, cellulitis and ear infections. 
OLS and IV regression estimates of the impact of Medicaid enrollment on ACS hospitalization rates are presented in Table VI. Outreach efforts (CBOs) serve as instruments for Medicaid enrollment in the first stage. As noted previously, because children in need of hospitalization are more likely to enroll in Medicaid, we would expect OLS estimates to be biased upward. In contrast, the IV results are designed to purge the estimates of this selection bias and reflect the impact of early enrollment and improved access to ambulatory care on ACS hospitalization rates. The equation estimated has the following form:

$$
\begin{aligned}
\mathrm{H}_{\mathrm{rzq}} & =\beta_{1} \text { Medicaid }_{\mathrm{rzq}}+\beta_{3} \text { Race }_{\mathrm{r}}+\beta_{4} \text { Quarter }_{\mathrm{q}}+ \\
& +\beta_{5} \text { AdultAdm }_{\mathrm{rzq}}+\beta_{6} \text { AFDC/TANF }_{\mathrm{rzq}}+\beta_{7} \text { Zipcode }_{\mathrm{z}}+\varepsilon_{\mathrm{rzq}}
\end{aligned}
$$

Where Medicaid represents the stock of Medicaid enrollment and for which I instrument using outreach as instruments in the first stage.

\section{B. Results: The Impact of Increased Take-up on Access to Primary Care as Measured by ACS Hospitalization Rates}

Table V contains the OLS and IV estimates of the impact of Medicaid enrollment on Medicaid hospitalizations for ACS and marker conditions, separately. The first panel is for all children, the second panel for Hispanic children only (for whom we expect a larger effect given the first stage results). The first four columns include zipcode*year and quarter fixed effects, the last four, zipcode*year*quarter fixed effects. The OLS estimates of the impact of Medicaid enrollment rates on ACS hospitalization rates for the full sample is positive and significant. In contrast, the IV estimates are negative and significant and suggest that an increase in total Medicaid enrollment of 25 percent results in a 3 percent decline in ACS hospitalizations. In contrast, the IV estimate of the impact of Medicaid enrollment on marker conditions is close to zero and imprecisely estimated (column 4). ${ }^{17}$ In the next four columns in which a more

\footnotetext{
${ }^{17}$ A test of overidentifying restrictions yields a chi-squared test statistic of 3.2 (p-value $=0.60$ ).
} 
restrictive set of controls is included (zipcode*year*quarter) the estimates are qualitatively similar: the OLS estimate of the impact of Medicaid enrollment on ACS hospitalizations is positive and significant, while the IV estimate is negative and significant and once again, the IV estimate of the impact of Medicaid enrollment on marker conditions is close to zero and insignificant.

The results based on Hispanic children only, however, and presented in the second panel are slightly different. Unlike the previous regressions based on the entire sample, the OLS estimated impact of Medicaid enrollment on hospitalizations is negative, but biased downward as the IV estimate is negative and larger (in absolute size) by about 25 percent than the OLS estimate. Both the OLS and IV estimates of the impact of Medicaid enrollment on marker conditions are positive and significant.

In order to provide additional evidence that the OLS estimated impact of Medicaid enrollment on avoidable hospitalizations among Hispanics is biased downward, I present OLS and IV estimates of the impact of Medicaid enrollment on ACS hospitalizations as a fraction of all hospitalizations (ACS/ALL) in the fifth and sixth columns of the second panel. This accounts for any changes in hospitalization patterns among Hispanic children for which I have not already controlled. Again, the OLS estimate of the impact of Medicaid enrollment on fraction of all hospitalizations that are ACS is negative and significant, but very much downward biased: the IV estimate is likewise negative and nearly five times as great.

\section{Conclusions}

The empirical results presented here represent some of the first to shed light on the causes and consequences of low take-up rates in the public program Medicaid. Using a unique data set with local area detail I am able to exploit exogenous variation in factors influencing take-up to identify the reasons why families may fail to take-up benefits that involve no out of pocket costs. These 
findings suggest that language barriers and immigration concerns increase the costs of take-up among Hispanic and Asian children. Furthermore, my findings suggest that increased enrollment as a result of outreach improves access to primary care as evidenced by a reduction in ambulatory care sensitive hospitalizations. Thus, outreach designed to address the concerns of low income families such as bilingual application assistance and a media campaign to increase awareness effectively increases take-up, enhances the efficiency of health care delivery and improves outcomes.

An outreach program that has the effect of limiting unnecessary or avoidable hospitalizations has the potential to reduce state expenditures substantially. Considering only the charges associated with ACS hospitalizations, which totaled \$284 million in California in 1996, an increase in early Medicaid enrollment of 25 percent would lead to a decline in ACS hospitalizations of 3.4 percent, which would result in savings of roughly $\$ 10.2$ million annually. This figure, however, is likely an underestimate of the cost-savings as it does not incorporate any of the potential savings associated with reduced emergency room visits, the increased labor supply of parents or the benefits to the child in terms of improved health as a result of avoiding 3500 days in the hospital (nor does it consider the relatively small additional costs associated with an increase in primary preventative care). 


\section{References}

Billings, John and Nina Teicholz (1990). "Uninsured Patients in District of Columbia Hospitals," Health Affairs, 9, 158-165.

Billings, John, Zeitel, Lisa, Lukomnik, Joanne, Carey Timothy, Black, Arthur and Laurie Newman (1993). "Impact of Socioeconomic Status on Hospital Use in New York City," Health Affairs, 12, 162-173.

Bindman, Andrew, Grumbach, Kevin, Ormond, Dennis, Komaromy, Miriam, Vranizan, Karen, Lurie, Nicole, Billings, John and Anita Stewart (1995). "Preventable Hospitalizations and Access to Care," Journal of the American Medicaid Association, 274, 305-311.

Craig, Peter (1991). "Costs and Benefits: A Review of Research on Take-up of Income-Related Benefits,” Journal of Social Policy, 20, 537-565.

Currie, Janet and Jonathan Gruber (1996), "Health Insurance Eligibility and Child Health: Lessons from Recent Expansions of the Medicaid Program", Quarterly Journal of Economics, May, 431-466.

Dafny, Leemore and Jonathan Gruber (2000). "Does Public Insurance Improve the Efficiency of Medical care? Medicaid Expansions and Child Hospitalizations," NBER working paper \#7555.

Epstein, Andrew (2001). "The Role of Public Clinics in Preventable Hospitalizations Among Vulnerable Populations," Health Services Research, 36, 405-410.

Fronstin, Paul (1998). "Sources of Health Insurance and Characteristics of the Uninsured: Analyses of the March 1998 Current Population Survey." Washington D.C: Employee Benefits Research Institute Issue Brief.

Gadmoski, Anne, Jenkins, Paul, and Melissa Nichols (1998). "Impact of a Medicaid Primary Care Provider and Preventive Care on Pediatric Hospitalization," Pediatrics, 101, 1-10.

Gill, James and Arch Mainous, "The Role of Provider Continuity in Preventing Hospitalizations," Archives of Family Medicine, 7, 352-357.

Goodman, David, Stukel, Therese, and Chiang-hua Chang (1998). "Trends in Pediatric Asthma Hospitalization Rates: Regional and Socioeconomic Differences," Pediatrics, 101, 208-213.

Graves EJ, Kozak LJ. Detailed diagnoses and procedures. National Hospital Discharge Survey, 1996. National Center for Health Statistics. Vital Health Stat 13(138). 1998.

Gruber, Jonathan (1997). "Medicaid and Uninsured Women and Children," Journal of Economic Perspectives, 11, 199-208.

Gruber, Jonathan (1999). “Medicaid,” NBER Working Paper \# 7829.

Hanratty, Maria (1996). "Canadian National Health Insurance and Infant Health," American Economic Review, 86, 276-284. 
Kasper, Judith (1986). "Health Status and Utilization: Differences by Medicaid Coverage and Income," Health Care Financing Review, 7,1-17.

McConnochie, Kenneth, Roghmann, Klaus, and Grgeory Liptak (1997). "Socioeconomic Variation in Discretionary and Mandatory Hospitalization of Infants: An Ecological Analysis," Pediatrics, 99, 774-784.

Parchman, Michael and Steven Culler (1994). "Primary Care Physicians and Avoidable Hospitalizations," Journal of Family Practice, 39, 123-128.

Parker, Jennifer and Kenneth Schoendorf (2000). "Variation in Hospital Discharges for Ambulatory Care-Sensitive Conditions among Children," Pediatrics, 106, 942-948.

Perry, Micahel (2001). "Medicaid and Healthy Families: Focus Groups with California Parents to Evaluation Medicaid and Healthy Families Programs," Kaiser Family Foundation.

Perry, Michael, Stark, Evan and Burgiaga Valdez (1998). "Barriers to Medicaid Enrollment and Ideas for Improving Enrollment: Findings from Eight Focus Groups in California with Parents of Potentially Eligible Children,” Kaiser Family Foundation \#1436.

Remler, Dahlia, Rachlin, Jason and Sherry Glied (2001). "What Can the Take-Up of Other Programs Teach Us About How To Improve Take-Up of Health Insurance Programs?" NBER Working Paper \#8185.

Ricketts, Thomas, Randolph, Randy, Howard Hilda Ann, Pathman, Donald and Timothy Carey (2001). "Hospitalization Rates as Indicators of Access to Primary Care," Health and Place, 7, 27 38.

Selden, Thomas, Banthin, JM and JW Cohen (1998). "Medicaid's Problem Children: Eligible but not Enrolled," Health Affairs, 17,192-200.

Shi, Leiyu, Samuels, Michael, Pease, Mary, Baily, Walter and Elizabeth Corley (1999). "Patient Characteristics Associated with Hospitalizations for Ambulatory Care Sensitive Conditions in South Carolina," Southern Medicaid Journal, 92, 989-998.

Short, Pamela and D. Lefkowitz (1992). "Encouraging Preventive Services for Low-Income Children: The Effect of Expanding Medicaid," Medical care, XXX, 76-80.

Stuber, Jennifer, Malloy, Kathleen, Rosenbaum, Sara and Karen Jones (2000). "Beyond Stigma: What Barriers Actually Affect the Decisions of Low-Income Families to Enroll in Medicaid?" Center for Health Services Research and Policy, George Washington University working paper.

Weissman, Joel, Gastonis, Constantine, and Arnold Epstein (1992). "Rates of Avoidable Hospitalization by Insurance Status in Massachusetts and Maryland," Journal of the American Medicaid Association, 268, 2388-2394. 
Table 1: Impact of CBOs on the Log of New Medicaid Enrollment

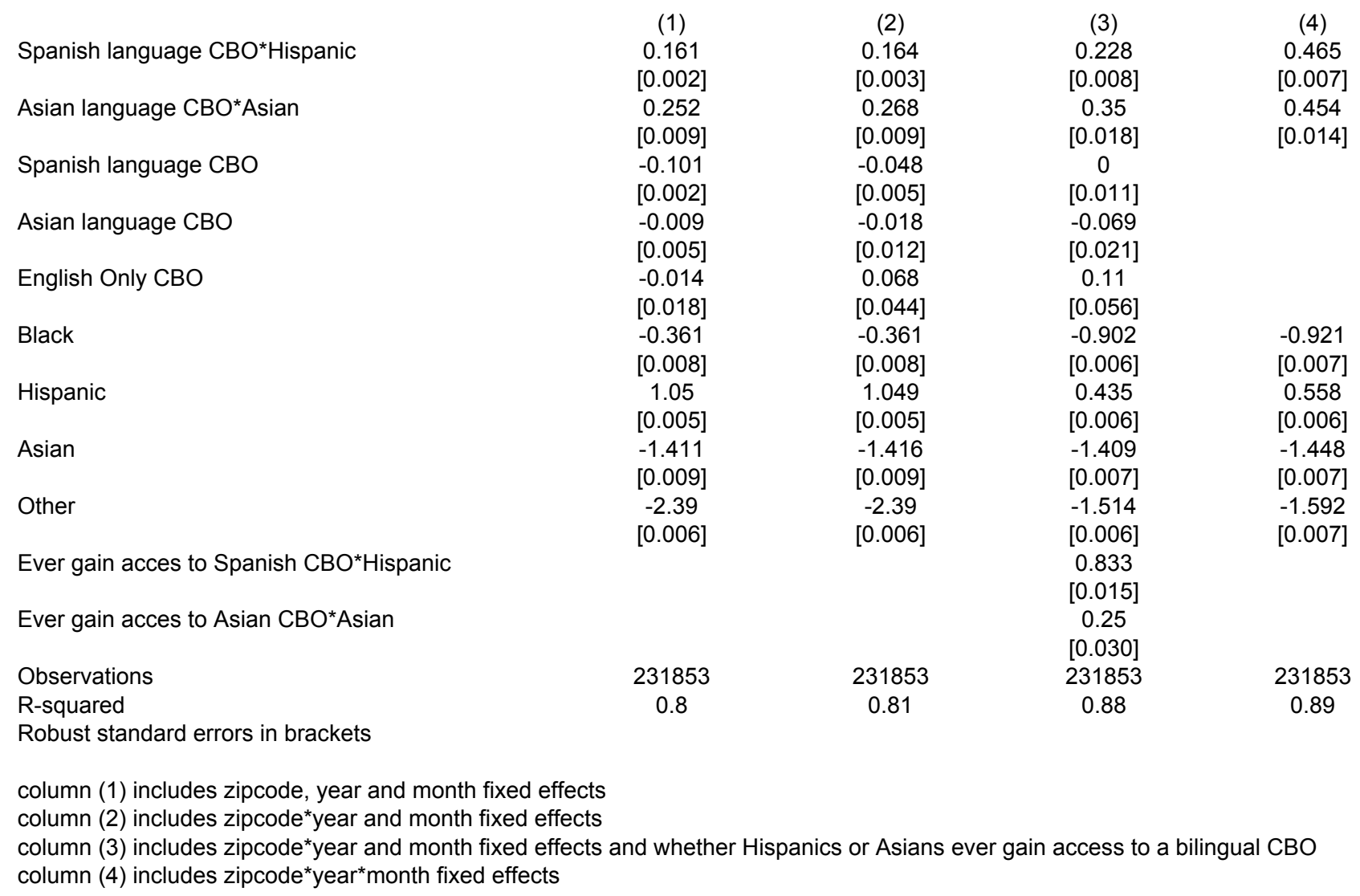


Table 2: Impact of CBOs on Total New Enrollment

non-welfare+welfare non-welfare welfare

Spanish language CBO*Hispanic

Asian language $\mathrm{CBO}^{*}$ Asian

Black

Hispanic

Asian

Other

Observations

R-squared

Standard errors in brackets

Table includes zipcode ${ }^{*}$ year ${ }^{*}$ month fixed effects
25.783

[0.733]

5.537

[1.531]

$-9.603$

[0.565]

23.015

[0.540]

$-16.21$

[0.592]

$-14.553$

[0.541]

231853

0.4
22.587

[0.323]

4.067

[0.674]

$-6.151$

[0.249]

18.637

[0.238]

$-7.962$

[0.261]

$-5.714$

[0.238]

231853

0.32
3.196

[0.457]

1.47

[0.955]

$-3.452$

[0.352]

4.378

[0.337]

$-8.247$

[0.369]

$-8.839$

[0.337]

231853

0.43 
Table 3: Exploring the Non-linear Nature of Bilingual Outreach

\begin{tabular}{|c|c|}
\hline \multirow{3}{*}{1 Spanish language СВО*Hispanic } & Ln(new total enrollment) \\
\hline & 0.743 \\
\hline & [0.018] \\
\hline \multirow[t]{2}{*}{2 Spanish language CBO*Hispanic } & 1.436 \\
\hline & {$[0.035]$} \\
\hline \multirow{2}{*}{3 Spanish language $\mathrm{CBO}$ *Hispanic } & 1.483 \\
\hline & {$[0.046]$} \\
\hline \multirow[t]{2}{*}{4 Spanish language $\mathrm{CBO}{ }^{*}$ Hispanic } & 1.76 \\
\hline & {$[0.080]$} \\
\hline \multirow[t]{2}{*}{5 + Spanish language $\mathrm{CBO}^{*}$ Hispanic } & 2.254 \\
\hline & [0.067] \\
\hline \multirow[t]{2}{*}{1 Asian language $\mathrm{CBO}^{*}$ Asian } & 0.428 \\
\hline & {$[0.032]$} \\
\hline \multirow[t]{2}{*}{2 Asian language $\mathrm{CBO}^{*}$ Asian } & 1.114 \\
\hline & {$[0.070]$} \\
\hline \multirow[t]{2}{*}{3 Asian language $\mathrm{CBO}^{*}$ Asian } & 1.804 \\
\hline & [0.098] \\
\hline \multirow[t]{2}{*}{4 Asian language $\mathrm{CBO}^{*}$ Asian } & 1.489 \\
\hline & {$[0.120]$} \\
\hline \multirow[t]{2}{*}{$5+$ Asian language $\mathrm{CBO}{ }^{*}$ Asian } & 2.179 \\
\hline & {$[0.140]$} \\
\hline \multirow[t]{2}{*}{ Black } & -0.919 \\
\hline & {$[0.007]$} \\
\hline \multirow[t]{2}{*}{ Hispanic } & 0.53 \\
\hline & {$[0.006]$} \\
\hline \multirow[t]{2}{*}{ Asian } & -1.448 \\
\hline & [0.008] \\
\hline \multirow[t]{2}{*}{ Other } & -1.59 \\
\hline & {$[0.007]$} \\
\hline Observations & 231853 \\
\hline R-squared & 0.69 \\
\hline Standard errors in brackets & \\
\hline
\end{tabular}


Table 4: Impact of TV Advertisements on the Log of New Medicaid Enrollment

Engligh TV in month of application

Spanish TV in month of application

Spanish TV in month of application*Hispanic

Spanish TV in month after application

English TV in month after applicaton

Spanish TV in month after application*Hispanic

Black

White

Hispanic

Asian

Observations

R-squared

Standard errors in brackets
(1)

$-0.001$

[0.009]

$-0.126$

[0.013]

0.215

[0.011]

1.248

[0.023]

2.075

[0.017]

3.046

[0.018]

0.362

[0.024]

3446

0.97
(2)

0.01

[0.013]

$-0.123$

[0.013]

0.218

[0.011]

$-0.037$

[0.019]

0.003

[0.015]

$-0.006$

[0.031]

1.248

[0.023]

2.076

[0.017]

3.042

[0.018]

0.362

[0.024]

3446

0.97
(3)

0.215

[0.021]

$-0.007$

[0.071]

1.373

[0.056]

2.058

[0.041]

3.056

[0.040]

0.475

[0.059]

3446

0.83

Columns (1) and (2) include DMA*year and month FE

Column (3) includes DMA*year*month FE 
Table 5: OLS and IV Estimates of the Impact of Medicaid Enrollment on Hospitalizations

\section{Full Sample}

Medicaid caseload (/100)

Hispanic

White

Asian

Black

Adult Admissions

Observations

R-squared

\begin{tabular}{|c|c|c|c|}
\hline \multicolumn{4}{|c|}{ Zipcode*year \& quarter FE } \\
\hline OLS & IV & OLS & IV \\
\hline ACS & ACS & Marker & Marker \\
\hline 0.043 & -0.035 & 0 & -0.001 \\
\hline$[0.004]$ & [0.009] & {$[0.001]$} & [0.001] \\
\hline-1.25 & -0.861 & 0.094 & 0.095 \\
\hline [0.069] & {$[0.079]$} & {$[0.012]$} & [0.013] \\
\hline-3.461 & -3.495 & -0.375 & -0.375 \\
\hline$[0.080]$ & {$[0.080]$} & {$[0.014]$} & [0.014] \\
\hline-3.512 & -3.736 & -0.473 & -0.473 \\
\hline [0.092] & [0.095] & {$[0.015]$} & [0.016] \\
\hline-2.953 & -3.445 & -0.515 & -0.517 \\
\hline$[0.097]$ & {$[0.110]$} & {$[0.016]$} & [0.018] \\
\hline 0.052 & 0.051 & 0.012 & 0.012 \\
\hline$[0.001]$ & {$[0.001]$} & {$[0.000]$} & [0.000] \\
\hline 124658 & 124658 & 124658 & 124658 \\
\hline 0.67 & 0.67 & 0.46 & 0.46 \\
\hline
\end{tabular}

$\begin{array}{cccc}\text { OLS } & \text { IV } & \text { OLS } & \text { IV } \\ \text { ACS } & \text { ACS } & \text { Marker } & \text { Marker } \\ -0.814 & -1.013 & 0.008 & 0.044 \\ {[0.033]} & {[0.135]} & {[0.005]} & {[0.019]} \\ 26313 & 26313 & 26313 & 26313 \\ 0.82 & 0.82 & 0.60 & 0.60\end{array}$

For Hispanics only, regressions include zipcode* ${ }^{*}$ ear \& quarter FE

Zipcode ${ }^{*}$ year*quarter FE

\begin{tabular}{cccc}
\multicolumn{4}{c}{ Zipcode $^{*}$ year $^{*}$ quarter FE } \\
\hline OLS & IV & OLS & IV \\
ACS & ACS & Marker & Marker \\
0.069 & -0.018 & -0.002 & -0.001 \\
{$[0.003]$} & {$[0.008]$} & {$[0.001]$} & {$[0.001]$} \\
-1.297 & -0.87 & 0.103 & 0.099 \\
{$[0.062]$} & {$[0.071]$} & {$[0.011]$} & {$[0.013]$} \\
-3.452 & -3.47 & -0.407 & -0.406 \\
{$[0.072]$} & {$[0.073]$} & {$[0.013]$} & {$[0.013]$} \\
-3.393 & -3.644 & -0.477 & -0.474 \\
{$[0.083]$} & {$[0.085]$} & {$[0.015]$} & {$[0.015]$} \\
-2.75 & -3.289 & -0.532 & -0.526 \\
{$[0.087]$} & {$[0.099]$} & {$[0.015]$} & {$[0.017]$} \\
0.054 & 0.053 & 0.014 & 0.014 \\
{$[0.001]$} & {$[0.001]$} & {$[0.000]$} & {$[0.000]$} \\
124658 & 124658 & 124658 & 124658 \\
0.78 & 0.78 & 0.6 & 0.6
\end{tabular}

$\begin{array}{cc}\text { OLS } & \text { IV } \\ \text { ACS/Total } & \text { ACS/Total } \\ -0.002 & -0.010 \\ {[0.001]} & {[0.004]} \\ 14510 & 14510 \\ 0.49 & 0.49\end{array}$

\section{R-Squared}

Standard errors in brackets

\section{Hispanics Only}

Medicaid caseload (/100)

Hispanics only, 
Figure I

Total Medicaid Enrollment Over Time

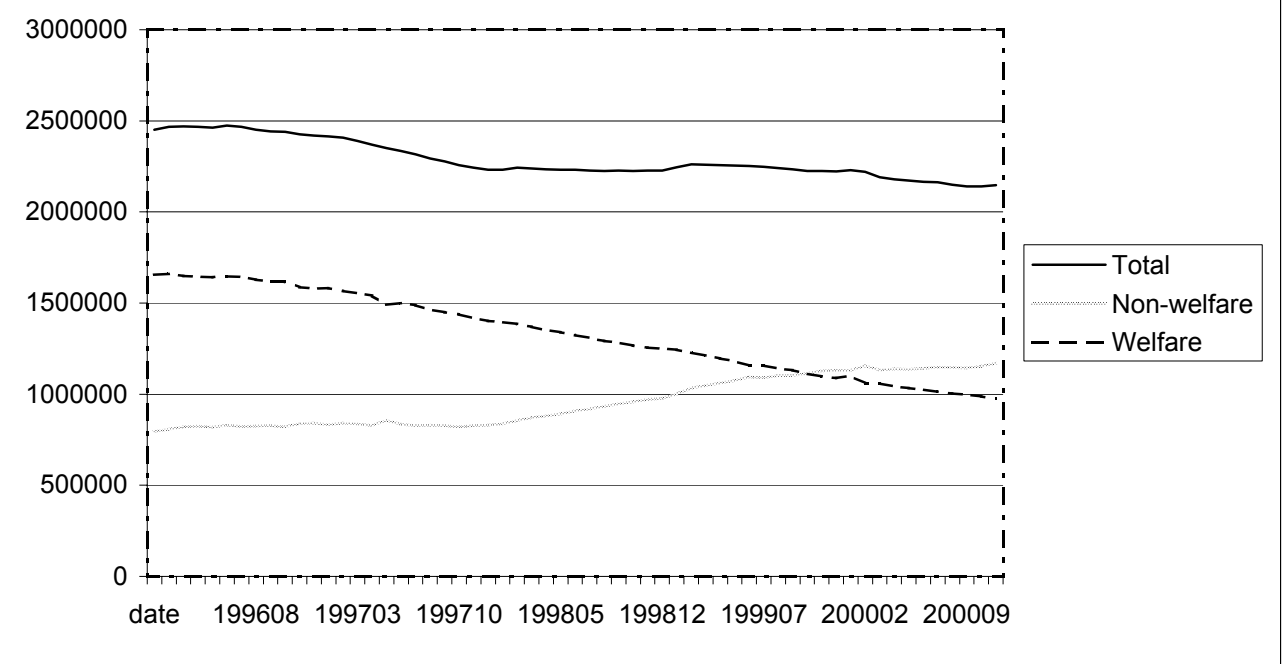

Figure II

Total Hispanic Medicaid Enrollment

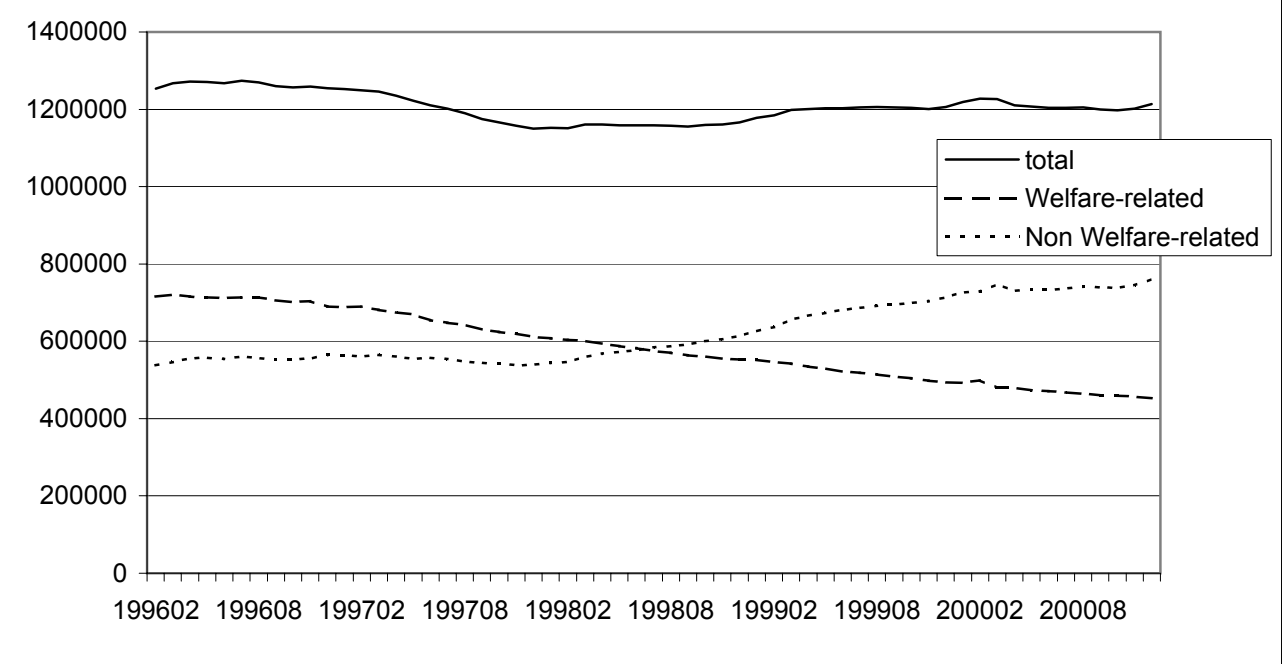


Figure III

Monthly Hispanic Non-Welfare Medicaid Enrollment by Bilingual CBO availability

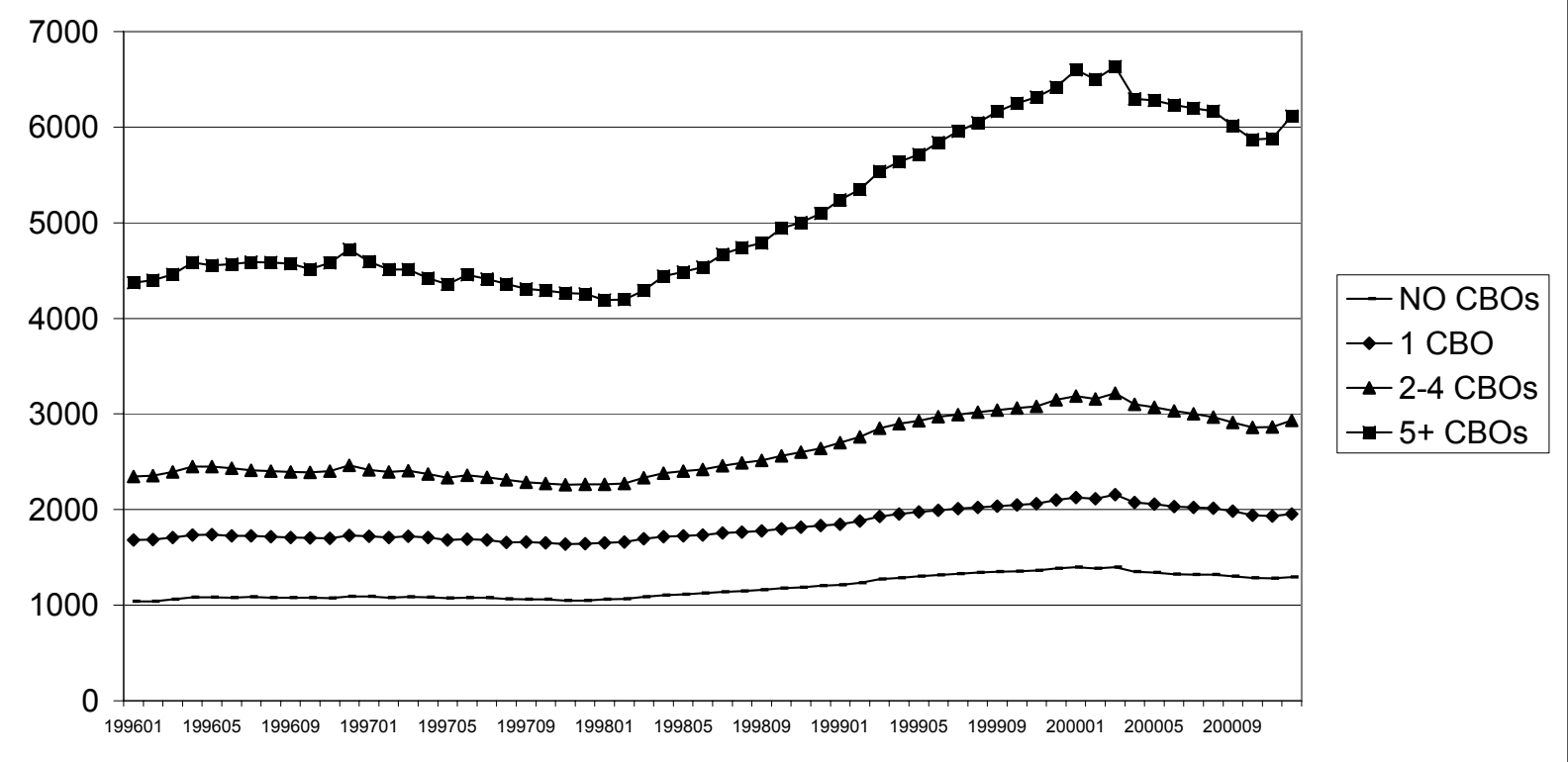


Appendix Table 1: Sample Means

\begin{tabular}{|c|c|c|c|}
\hline & All & Hispanic & Asian \\
\hline \multirow[t]{2}{*}{ Monthly New Enrollment } & 68.99 & 143.77 & 8.79 \\
\hline & $(0.17)$ & $(0.44)$ & $(0.04)$ \\
\hline \multirow[t]{2}{*}{ Monthly New Enrollment - Welfare Related } & 17.24 & 31.26 & 3.33 \\
\hline & $(0.04)$ & $(0.11)$ & $(0.02)$ \\
\hline \multirow[t]{2}{*}{ Monthly New Enrollment - Non Welfare Related } & 51.75 & 112.52 & 5.45 \\
\hline & $(0.14)$ & $(0.35)$ & $(0.04)$ \\
\hline \multirow[t]{2}{*}{ Monthly Enrollment } & 2140.94 & 4210.48 & 736.72 \\
\hline & $(4.99)$ & (12.68) & $(4.02)$ \\
\hline \multirow[t]{2}{*}{ Monthly Enrollment - Welfare Related } & 1157.33 & 2103.12 & 608.54 \\
\hline & (2.63) & $(6.65)$ & $(3.66)$ \\
\hline \multirow[t]{2}{*}{ Monthly Enrollment - Non Welfare Related } & 983.6 & 2107.36 & 128.18 \\
\hline & (2.56) & $(6.58)$ & $(0.62)$ \\
\hline \multirow[t]{2}{*}{ ACS Hospitalizations } & 6.79 & 10.48 & 1.48 \\
\hline & $(0.03)$ & $(0.09)$ & $(0.02)$ \\
\hline \multirow[t]{2}{*}{ Marker Hospitalizations } & 0.85 & 1.04 & 0.2 \\
\hline & $(0.004)$ & $(0.01)$ & $(0.004)$ \\
\hline \multirow[t]{2}{*}{ ACS Hospitalizations per 1000 Medicaid } & 3.17 & 2.49 & 2.01 \\
\hline & $(0.02)$ & $(0.02)$ & $(0.02)$ \\
\hline \multirow[t]{2}{*}{ Marker Hospitalizations per 1000 Medicaid } & 0.40 & 0.25 & 0.27 \\
\hline & $(0.0002)$ & $(0.0002)$ & $(0.0004)$ \\
\hline
\end{tabular}

All means weighted by number of families of same race below $200 \%$ FPL in zipcode Standard errors below means in parentheses 